\title{
Aspects of the Olutura Syllable System
}

\author{
Everlyn Etakwa*, Mohamed Akidah, Ayub Mukhwana \\ Department of Linguistics and Languages, University of Nairobi, Kenya
}

Received September 25, 2019; Revised November 16, 2019; Accepted November 23, 2019

Copyright $\bigcirc 2019$ by authors, all rights reserved. Authors agree that this article remains permanently open access under the terms of the Creative Commons Attribution License 4.0 International License

\begin{abstract}
The aim of this study was to examine the syllable structure types that occur in Olutura and their constitution. The study identifies the syllable structures of Olutura by showing the sound segments that constitute each of them. The data was analyzed using Generative CV Phonology which enabled us to identify the syllable structures of Olutura by showing the sound segments that constitute each of them. A purposive sampling technique was used to identify native Olutura speakers and to categorize the data into the required categories for analysis. Examples of words in which these sound segments occur are provided in order to show their positions in the syllable structures of Olutura. From the data analysis, Olutura has a total of seven syllable structures: $\mathrm{V}, \mathrm{VV}, \mathrm{CV}, \mathrm{CVV}, \mathrm{CCV}$, $\mathrm{CGV}$ and GGV. This language variety has an open syllable structure because it does not allow codas. The VV and GGV syllable structures are marked because of their sparse occurrence in the overall phonological system of the language.
\end{abstract}

Keywords Olutura, Syllable, Nucleus, Phonotactics, Word Position, CV Phonology

\section{Introduction}

This research paper is about the constitution of the syllable structures of Olutura and their prevalent word positions. Olutura is a variety of the Luyia continuum of dialects that is yet to be classified [1,2]. It is spoked in Mungore location, Bumula area of Bungoma County. The Luyia language is spoken in Western Kenya. The Luyia dialects that are already classified are Lulogoli, Luwanga, Lunyole, Lukabras, Lukhayo, Lusamia, Lutsotso, Olunyala (B), Olunyala(K), Lubukusu, Lutachoni, Lumarachi, Lwitakho, Lutiriki, Lwisukha, Lukisa, Lumarama and Lusonga [1]. Olutura is a variety that was not considered as part of the Luyia continuum of dialects until its mention by Marlo [2]. Olutura is yet to be determined as either a distinct dialect or part of one of the already existing ones. The general purpose of the study was to examine the syllable structures of Olutura and how they are affected by the phonotactics of this dialect. The study contributes to the documentation of Olutura which is understudied and to its objective generalization to other Luyia dialects and Bantu languages in general.

\section{Methodology}

The research was carried out in Mungore location, Bumula Sub-county, Bungoma County in Western Kenya. A purposive sampling technique was used to pick the respondents from the research location. Interview schedules and a sound recorder were used as data collection tools. The study used a total of five respondents aged between 40 and 60 years with adequate mastery of Olutura. The respondents were speakers of Olutura who have lived in Mungore for a long time and who, not only exhibited sufficient competence in the subject dialect, but also were able to identify words that are not from Olutura. This attribute was necessary because most speakers of Olutura also speak other dialects from the neighbouring speech communities. The data collection procedure involved the use of oral interviews and the information was recorded using a sound recording machine. The data was transcribed and lists prepared. Purposive sampling was then used to group the data into the required word categories of nouns, verbs, adjectives and demonstratives as single lexical items. A total of 120 words were purposively sampled and put into the envisioned four categories for analysis. Using Generative CV phonology, the syllable boundaries were drawn for each of the words before identifying the syllable structure types. The syllable types were then examined in terms of the onset and nucleus to establish the composition of these syllable elements for each syllable type.

\section{Overview of the Syllable}

The syllable is very vital for, not just uncovering the sound segments in a language, but also their internal 
structure because segments are not uttered in isolation. This is in accordance with Katamba [3] who notes that the syllable is very vital in the understanding of the phonological processes of any language. Bauer [4] concurs with Katamba [3] that quite a number of phonological processes are determined by boundaries of units larger than the segment [2]. An analysis of the syllable structure of Olutura in terms of the onset and nucleus as constituents of the syllable can only be possible by presenting the distribution of the phonemes as the basic units of a word. We note here that the coda, as an element of the syllable in accordance to CV Phonology was not used in this study because Olutura does not have codas by virtue of having open syllables. According to Hooper [5], the CV is the optimal syllable because it is the syllable that is general in all languages and therefore, universal. A description of the phonological syllable enables an analysis that goes beyond the phonetic sequencing that could easily leave some elements unrealized. In accordance to Generative CV Phonology, core syllabification refers to the idea that each language has its preferred syllable structure [6]. Many linguists have noted that there is a cross-linguistic preference for certain types of syllable structures and syllable sequences and that this is what leads to certain syllable types being less marked than others $[7,6,8]$. Olutura, like other Bantu languages has open syllables and so the current study focused on the constitution of the onset in this language variety to establish the phonotactics that are at play in its formation. The study also shows that some syllable types in Olutura are marked by virtue of their limited occurrence in certain word positions and in the general Olutura lexical system.

\section{Results and Discussion}

\subsection{The V Syllable Structure}

This syllable structure is referred to as the zero onset syllable (Ø) because it is composed of only one vowel segment is analyzed in Generative CV Phonology as only having the NUCLEUS $(\mathrm{N})$. Apart from $(\mathrm{N})$, all the other categories may be empty [9].The CV Phonology syllable tier model is used in Figures 1 (a) and (b) to show how syllabification takes place in the $\mathrm{V}$ syllable structure in Olutura.

The V syllable structure can occur in all the three word positions, that is, initial, medial and final in Olutura. Figure 1(a) shows that the first syllable of the word ino has one $\mathrm{V}$ syllable while Figure 1(b) shows a syllable tree with V syllables that follow each other but are heterosyllabic. The first two syllables in the word aenda in 1(b) are short because each is composed of only a vowel. The first zero onset syllable is at word initial position while the second one is at word medial position. This example shows that in Olutura, zero onset syllables can be adjacent to each other in a word.

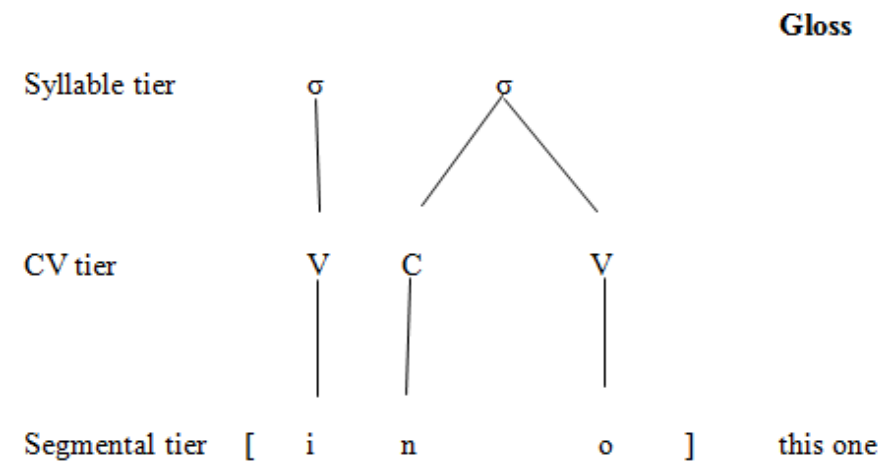

Figure 1(a). Single V syllable

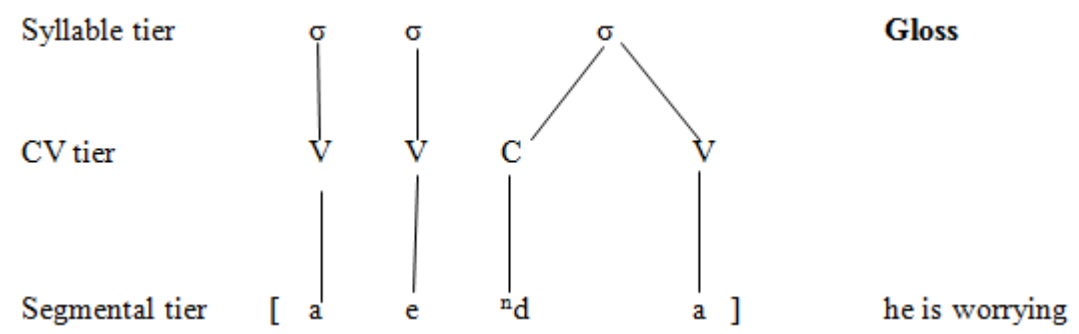

Figure 1(b). Heterosyllabic V syllables 


\subsection{The VV (V:) Syllable Structure}

The VV syllable is made up of two similar vowels, hence tauto-syllabic. This syllable is zero onset as exemplified in the words in 1. It only occurs at word initial position in Olutura, and, is therefore, marked.

1. Olutura VV Tautosyllabic Syllable Structure

i. [a:.na] s/he is giving

ii. [a:.mbja] s/he is lighting, e.g. fire

iii. [e:nd I am worrying

iv. [i:.ne] go down to avoid v. [o:.nga] fail to leave home

A CV phonology analysis shows the structure in Figure 2 in which the syllable has a branching nucleus similar to the one in the CVV syllable structure but the only difference is that the structure in Figure 2 is onsetless.

A comparison of syllable trees of the VV to the CVV syllable structure can clearly show the difference between them. Generative CV Phonology tier model is used by juxtaposing Figures 3 (a), (b) and (c). The three figures show the syllabification of Olutura words to demonstrate the difference between the V and VV syllable structures.
Syllable tier
CV tier
Segmental tier

Syllable tier

CV tier

Segmental tier
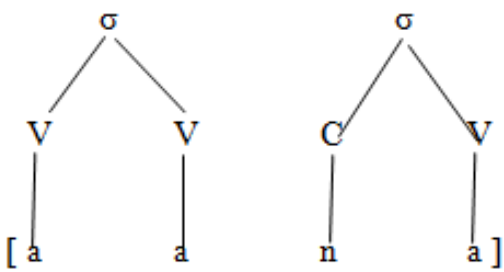

he is giving

Figure 2. Olutura VV syllable tree
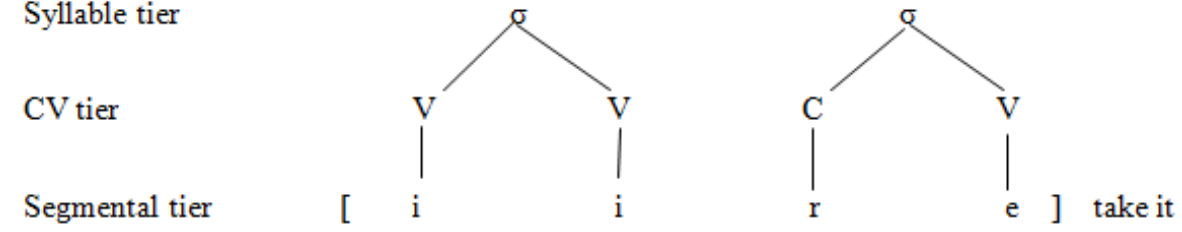

Figure 3 (a). $\quad$ Olutura word initial VV syllable (tautosyllabic)

Syllable tier
CV tier
Segmental tier
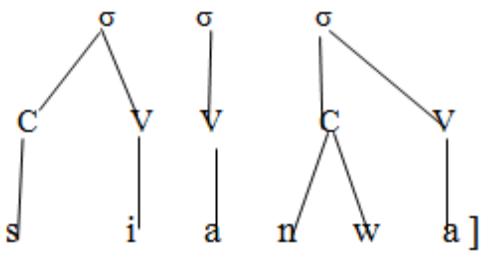

gift

Figure 3(b). Olutura word medial V syllable (heterosyllabic)

Syllable tier

CV tier<smiles>O[V]</smiles>

Segmental tier

[

- ]

there

Figure 3 (c). Olutura word initial V syllable (heterosyllabic) 
In Figure 3 (a), the VV occurs in the same syllable and the syllable concerned is a heavy one by virtue of having a long vowel. This syllable occurs in word initial position and it has a branching nucleus. Figure 3 (b) shows the V syllable which occurs in word medial position and is bound on either side by CV syllables. This means that the two vowels in the middle of the Olutura word esianwa are syllabified in different syllables as [e.si.a.nwa]; hence heterosyllabic. This means that Olutura allows hiatus in certain contexts, an observation that is also made by Casali [10]. In Figure 3 (c), the word that is analyzed has two syllables both of which do not have onsets and are syllabified as [a.o], that is; V.V. This is different from the syllabification in 3(a) which results in [ii.re] with two vowel elements in the same syllable, that is; VV.CV which makes the initial syllable tautosyllabic.

\subsection{The CV Syllable Structure}

The CV syllable structure is composed of one consonant and one vowel sound and is, therefore referred to as the onset syllable [11]. The CV structure is the optimal syllable structure in the Luyia continuum of dialects and other Bantu dialects [12].This, therefore, is presumably the case for Olutura. The occurrence of the CV syllable structure is very high in Olutura since the onset can be formed by any of the consonants that occur in the phonemic inventory of this language. This is shown using the data in 2.

2. CV syllable structure

\begin{tabular}{|c|c|c|c|c|c|}
\hline & & & Input & output & Gloss \\
\hline \multirow[t]{4}{*}{ (a) } & Plosives & $/ \mathrm{k} /$ & /kula/ & [ku.la] & buy \\
\hline & & & /kira/ & [ki.ra] & cause to \\
\hline & & $/ \mathrm{p} /$ & /puruxa/ & [piruxa] & fly \\
\hline & & $/ \mathrm{t} /$ & /toola/ & [to:.la] & pick \\
\hline \multirow[t]{6}{*}{ (b) } & Fricatives & $/ \mathrm{f} /$ & /funa/ & [fu.na] & break/harvest \\
\hline & & & /fiina/ & [fi:.na] & press \\
\hline & & $/ \mathrm{s} /$ & /simia/ & [si.mja] & put off a fire \\
\hline & & & /soma/ & [so.ma] & read \\
\hline & & $\mid x /$ & /xesia/ & [xesja] & greet \\
\hline & & & /xula/ & [xu.la] & grow \\
\hline \multirow[t]{6}{*}{ (c) } & Nasals & $/ \mathrm{m} /$ & /mira/ & [mi.ra] & swallow \\
\hline & & & /mala/ & [ma.la] & finish \\
\hline & & $/ \mathrm{n} /$ & /nuuna/ & [nu:na] & suckle \\
\hline & & & /niina/ & [nii.na] & climb \\
\hline & & $/ \mathrm{y} /$ & /ineeni/ & [ine:ni] & fish \\
\hline & & & /inuunda/ & [iju:nda] & rubbish \\
\hline \multirow[t]{4}{*}{ (d) } & Liquids & $/ \mathrm{l} /$ & /luma/ & [lu.ma] & bite \\
\hline & & & /loora/ & [lo:ra] & dream \\
\hline & & $/ \mathrm{r} /$ & /leera/ & [le:ra] & bring \\
\hline & & & /ruma/ & [ru.ma] & send \\
\hline \multirow[t]{10}{*}{ (e) } & Glides & $/ \mathrm{w} /$ & /wuula/ & [wu:.la] & husk grains \\
\hline & & & /wiina/ & [wi:.na] & who is it? \\
\hline & /f/ prenasals & $/ \mathrm{mb} /$ & /mbira/ & [mbi.ra] & I am taking/passing \\
\hline & & & /fwimba/ & [fwi.mba] & I am swelling/covering \\
\hline & & $/ \mathrm{mbw} /$ & /mbwao/ & [mbwa.o] & I am going home/leaving \\
\hline & & /nd/ & /ndala/ & [nda.la] & one \\
\hline & & & /ndola/ & [ndo.la] & I am seeing \\
\hline & & /ndw/ & /ndwaala/ & [ndwa:la] & I am sick/getting sick \\
\hline & & & /indwasi/ & [i.ndwa.si & alergy \\
\hline & & /ngw/ & /ygwa/ & [ygwa/ & I am falling/ failing \\
\hline
\end{tabular}


The CV syllable structure of Olutura is represented in Figure 4 using the CV Phonology as expounded by Clements \&Keyser [6].

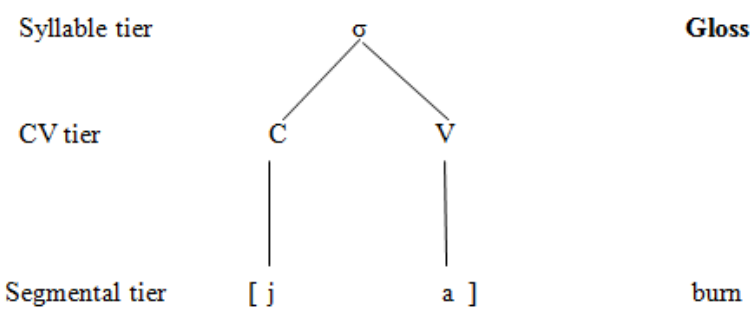

Figure 4. Olutura CV tier model

Following McCarthy \& Prince [13], the CV tier model is used to specify the exact segments that occupy the skeletal slots. This ensures that the segments correspond according to the tiers and the conjugations for each template are captured. Olutura has $\mathrm{C}$ elements that have clusters which are captured using the $\mathrm{CV}$ tier models in the figures in 5. This means that in Olutura, the onset in the CV syllable structure is formed by either one grapheme or several graphemes.

Figures 5(a) and (b) show a CV tier model with a complex onset using the Olutura words imbwa and tsia, respectively.

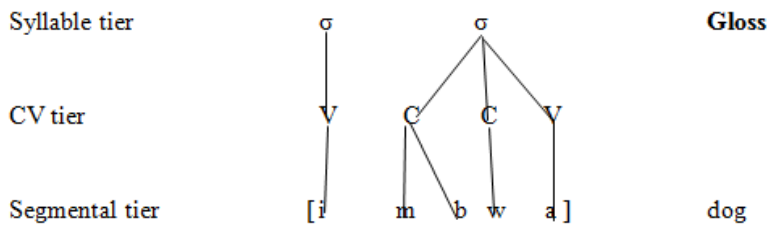

Figure 5 (a). Olutura internally complex onset with /mbw/

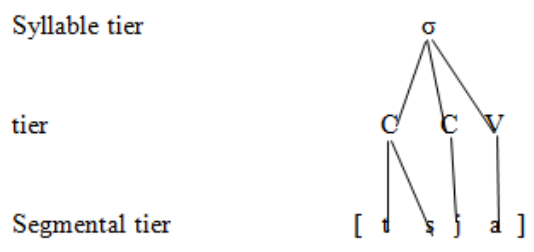

Figure 5(b). Olutura internally complex onset with /tsj/

Although all the vowel sounds of Olutura occur in the nucleus position in the CV syllable structure, this occurrence is very minimal when the onset is composed of the prenasalized and labialized sounds.

\subsection{The CVV (CV:) Syllable Structure}

Olutura has the CVV (CV:) syllable structure which is composed of one consonant and two similar vowel elements. The idea that the vowels concerned must be similar is vital in this particular structure because a dissimilarity would lead to either diphthongs or vowels being syllabified in different syllables. The long vowel is transcribed in this study as CV:.
In Olutura, the CV: syllable structure can occur in the word initial position in basic verbs and adjectives and in word medial position in common nouns as seen in 3.

3. Olutura CV: syllable in basic verbs

\begin{tabular}{|c|l|l|l|}
\hline & UR & SR & Gloss \\
\hline (i) & $/ \beta$ oola/ & {$[\beta$ o:la $]$} & say \\
\hline (ii) & /jiima/ & [ji:ma $]$ & hunt \\
\hline (iii) & $/$ jaala/ & [ja:la] & $\begin{array}{l}\text { make/spread a bed/ } \\
\text { put on trial }\end{array}$ \\
\hline (iv) & $/$ fuuva/ & [fu: $\beta$ a] & throw \\
\hline (v) & $/$ xesja/ & [xe:sja] & greet \\
\hline (vi) & $/$ xuula/ & [xu:la] & uproot \\
\hline (vii) & /siteere/ & [site:re] & day time \\
\hline (viii) & /emiima/ & [e.mi:.ma] & manners \\
\hline (ix) & /aambi/ & [a:.mbi] & near \\
\hline (x) & /wuula/ & [wu:la] & husk grains \\
\hline
\end{tabular}

In most cases the CV: occurs at word initial position in verbs but automatically moves to the second syllable when the verb gets a prefix as in 4 .

4. Occurrence of CV: in the second syllable

\begin{tabular}{|c|l|l|l|}
\hline & UR & SR & Gloss \\
\hline (i) & $/$ avoola/ & [a. $\beta$ o:.la $]$ & he is saying \\
\hline (ii) & $/$ ajiima/ & [a.ji:.ma $]$ & he is hunting \\
\hline (iii) & $/$ oxuula/ & [o.xu:.la] & you are uprooting \\
\hline
\end{tabular}

Some exceptions are noted with certain verbs retaining the CV syllable word initially like the verb [ja:la] in 5 (iii). Interestingly [ja:.la] only changes the consonant in the onset to indicate the aspect of person unlike the rest of the verbs which get a new $\mathrm{V}$ syllable before them. More interesting is the observation that the new sound segments that show the different persons are all different. The occurrence in which there is sequential alternation is shown in 5.

5. Different onset phonemes showing person

$$
\text { /- ala/ }
$$

i. [na:la] I am spreading ( $1^{\text {st }}$ person)

ii. [wa:.la] you are spreading $\left(2^{\text {nd }}\right.$ person $)$

iii. [ja:.la] he is spreading ( $3^{\text {rd }}$ person)

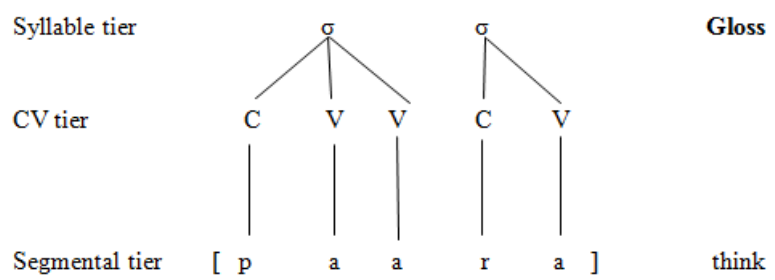

Figure 6. Olutura CV: syllable

In the CV: structure, a difference is noted in the word yaala which can either mean to spread a bed or to put someone on trial. The occurrence in 5 (i) applies to the Olutura word that means to spread a bed because to 
prosecute behaves like the rest of the basic verbs in 4 which do not realize a different consonant in the onset. The representation of the CV: syllable structure in Olutura is shown in Generative CV Phonology in Figure 6 using the Olutura word paara.

The representation in Figure 6 shows that the first syllable of the word [pa:ra] has a branching nucleus by virtue of having two VV slots on the CV tier. In Generative CV Phonology, length, which is constituted by the timing units of the $\mathrm{C}$ or $\mathrm{V}$ elements in a syllable, is what determines syllable weight. This means that in Olutura, the $\mathrm{CV}$ : is a heavy syllable by virtue of having a nucleus with two timing slots. This is unlike the CV syllable which has only one V slot. In Olutura, the CV: syllable structure can occur in word initial position in verbs and adjectives and in word medial position in common nouns as seen in 6 .

6. Olutura CV syllable structure

\begin{tabular}{|c|l|l|l|}
\hline & UR & SR & Gloss \\
\hline (i) & /wuula/ & {$[$ wu:la $]$} & husk grains \\
\hline (ii) & /fuuva/ & {$[\mathrm{fu}: \beta a]$} & throw \\
\hline (iii) & /aambi/ & {$[\mathrm{a}: . m b i]$} & near \\
\hline (iv) & /aana/ & {$[\mathrm{a}: \mathrm{na}]$} & he is giving \\
\hline (v) & /emiima/ & {$[$ e.mi:.ma $]$} & manners \\
\hline
\end{tabular}

\subsection{The CCV Syllable Structure}

The CCV syllable structure in Olutura has three types, namely; CCV, CGV and GGV. Olutura has a syllable structure that is composed of a consonant that is not an approximant, an approximant and a vowel. This sequence results in the occurrence of what is, in our view, a complex syllable discussed in this section. Other scholars discussing Luyia dialects also report the existence of this kind of syllable structure and refer to it as CGV or CSV $[14,15]$.

In this study, it should be noted that /w/ and /j/ occur as separate phonemes which can only form onsets in the phonology of Olutura, and, therefore, form a cluster with whatever other consonants they combine; hence the analysis of this structure as a CCV type. The consonants with which they form a cluster also occur as separate sound segments in the phonology of this language, hence a cluster of the CCV structure when they combine. The occurrence of the CGV type of CCV syllable structure is marked because not all consonants in the phonology of Olutura can combine to form a cluster in this syllable type. Due to perceptual and articulatory reasons, there are constraints on the sound segments that can combine to form syllables [16, 17]. This is the reason why many languages, and in particular Bantu languages, use various phonological processes to achieve syllable structures that are simple because the dialect does not allow complex ones. Of the two glides, /w/ combines with all the consonants and consonant clusters in Olutura. Its combination with the velar nasal $/ \mathrm{y} /$ and the alveolar affricate $/ \mathrm{ts} / \mathrm{is}$, however, very rare and therefore marked. The formation of the CGV type of CCV syllable is shown in 7.

7. Olutura CGV syllable structure

\begin{tabular}{|c|l|l|l|}
\hline & CGV syllable & Word & Gloss \\
\hline (i) & $/ \mathrm{fw} /$ & {$[$ fwa:la] } & dress up \\
\hline (ii) & $/$ tw/ & {$[$ itwasi] } & female cow \\
\hline (iii) & $/ \mathrm{ndw} /$ & /ndwa.la/ & I am sick \\
\hline (iv) & $/ \mathrm{ndw} /$ & {$[$ indwasi] } & allergy \\
\hline (v) & $/ \mathrm{ngw} /$ & {$[$ ggwa] } & I am falling \\
\hline (vi) & $/ \mathrm{sj} /$ & {$[$ sja] } & grind \\
\hline (vii) & $/$ tjo/ & [esitjo:li] & sheep pen \\
\hline
\end{tabular}

The examples in 5 show how Olutura forms consonant sounds from secondary articulation and, therefore, expanding its phonetic inventory beyond the consonants that arise from primary articulation. The other type of CCV syllable structure in Olutura can also be composed of two glides in the onset which are followed by a vowel in the nucleus. This brings up the GGV sequence discussed in this study as a CCV type syllable structure. Examples of Olutura words with the GGV sequence are shown in 8.

\section{Olutura GGV type of CCV syllable structure \\ i. [ $\quad$ [ßjwa] being played, e.g. a ball (passive) \\ ii. [tsifujwe] being washed, e.g. clothes \\ iii. [ja:jwa] it is being grazed \\ iv. [kajojwa] they are being scooped \\ v. [tsjejwa] they are being swept \\ vi. [siejwe] Kakamega town}

In Olutura, the GGV type of the CCV syllable structure is mostly used to show the passive voice as exemplified in examples 6 (i) to (v).The data analyzed revealed that this syllable structure mainly occurs in verbal constructions. Only one example was attested for nouns in this study and this means that the GGV sequence also occurs in nouns, however minimal. This gives it the quality of markedness because it does not occur in all word categories and in all three word positions in verbs and nouns. Our discussion on the existence of the CCV syllable structure is in agreement with other scholars on Bantu languages who view it as such instead of simplifying the segment sequences to the canonical and easier to perceive CV syllable structure. Savala [17] and Etakwa et al [18] also report the occurrence of the CCV syllable onset in the Luyia dialects of Lwitakho and Olunyala (K) respectively. The syllabification of these combinations as CV would mean that either the glide or fricative would be part of the onset or the nucleus. By virtue of their capability to form onsets in Olutura, glides are consonants and cannot, therefore, form the nucleus as shown using Generative CV phonology in the figures in 7. Figure 7(a) shows the CCV structure type with a pure consonant and a glide in the onset, Figure 7 (b) shows the CCV syllable structure with a consonant and a glide while 7 (c) shows that the second syllable of the word sieywe has two glides in the onset and a vowel; hence the GGV sequence. 


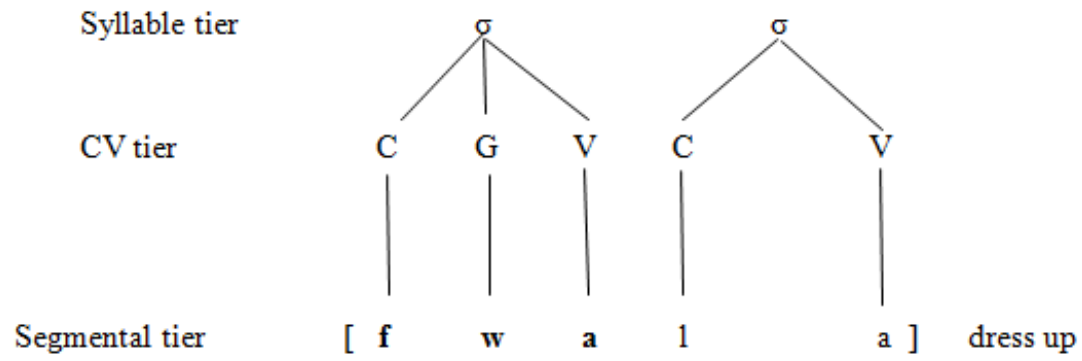

Figure 7 (a). Olutura CGV syllable structure with /w/
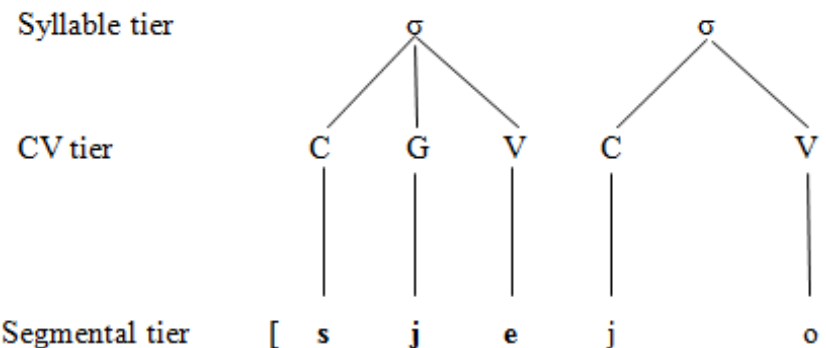

Segmental tier

Figure 7(b). Olutura CGV syllable structure with $/ \mathrm{j} /$

Syllable tier
CV tier
Segmental tier
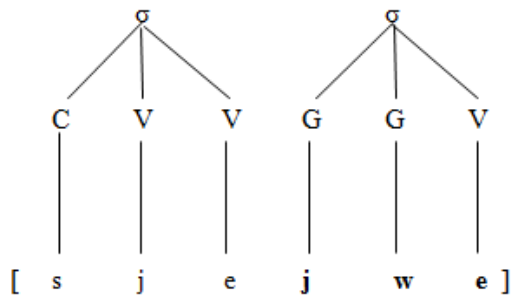

o ]

broom

Figure 7(c). Olutura GGV syllable structure

Figures 7 (a), (b) and (c) show the various types of the occurrence of the CCV syllable structure (in bold) in Olutura. This is not the same as the CV structure which has the prenasalized sound shown in Figure 8. The examples in the figures in 7 show that the consonant elements in the onset do not branch from the CV tier level. This is one of the points that this study is using to explain the foregoing argument that they are distinct elements unlike the $\mathrm{C}$ elements in Figure 8 which are combined and, therefore behave as one $\mathrm{C}$ element. Another argument for the CCV structure is that, one of the consonants that constitute it does not occur in the phonemic inventory of Olutura as a single, distinct phoneme. Secondly, the other consonant in the structure occurs as a phoneme and forms a syllable onset in this dialect. Thirdly, the second consonant in the pair cannot form the nucleus because consonants do not occur in nucleus position in Olutura.

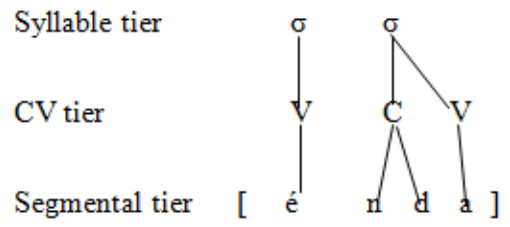

Figure 8. Olutura CV syllable with a prenasalized sound 


$\begin{array}{lll}\text { Stronger } & \text { Voiceless plosives } & {[\mathrm{p}, \mathrm{t}, \mathrm{f}, \mathrm{k}]} \\ & \text { Voiceless fricatives } & {[\mathrm{f}, \mathrm{s}, \mathrm{x}, \mathrm{ts}]} \\ & \text { Voiced fricative } & {[\beta]} \\ & \text { Prenasals } & {[\mathrm{mb}, \mathrm{nd}, \mathrm{nf}, \mathrm{ng}, \mathrm{nz}]} \\ & \text { Nasals } & {[\mathrm{m}, \mathrm{n}, \mathrm{n}, \mathrm{r}]} \\ & \text { Liquids } & {[1, \mathrm{r}]} \\ & \text { Labials } & {[-\mathrm{w}]} \\ \text { Weaker } & \text { Glides } & {[\mathrm{w}, \mathrm{j}]}\end{array}$

Figure 9. Olutura Consonant Strength Scale

Olutura has a simple syllable structure and that the $\mathrm{CV}$ is the optimal syllable. The CCV is, therefore, a marked syllable structure in this dialect and the motivation for its occurrence needs to be established. The concept of Sonority Sequencing Principle (SSP) can be used to explain the consonants that combine in the CCV structure in Olutura. SSP stipulates that sonority, which is about the acoustic properties of a sound, increases towards the syllable nucleus [19]. This can help to predict the possible clusters and syllabification in a given language. A consonant strength scale of Olutura is suggested in Figure 9 to show the syllabification that appertains in this dialect with regard to the onset in the CCV syllable structure.

In Olutura, glides can easily combine with any other consonant but the other consonants cannot combine with each other in the onset position. A combination of / $/$ / and $/ \mathrm{s} /$ is allowed because both consonants have the same place of articulation of alveolar and /s/ is lower on the sonority scale in Figure 9 than /t/ and that is why the latter is nearer the nucleus in the onset. For a speaker of Olutura, it is easier to articulate /t/ as a pre-onset in the combination with /s/ without the intervention of a vowel as it would be with /s/ forming the pre-onset.

\subsection{The CCV Syllable Structure with Affricates}

Olutura has a CCV syllable structure which comprises of two affricates and a glide in the onset. This brings the occurrence of a complex onset as demonstrated in the words in 9 and in Figure 9, respectively.

9. Olutura CCV syllable structure with an affricate onset

\begin{tabular}{|c|l|l|}
\hline & CCV & Gloss \\
\hline (i) & /tswe/ & spotlessly clean \\
\hline (ii) & /tswi/ & (a swear word) \\
\hline (iii) & /ama $\beta$ a:tswa/ & thighs \\
\hline
\end{tabular}

A generative phonology analysis of the CCV syllable structure with an affricate onset is exemplified in Figure 10.

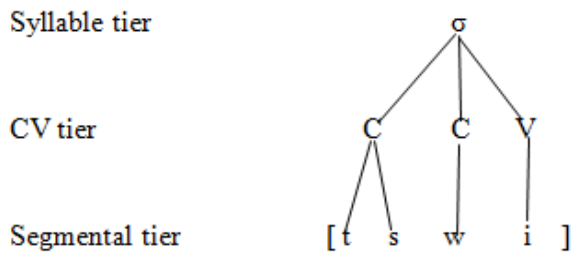

Figure 10. Olutura affricate CCV syllable structure

In Figure 10, the first $\mathrm{C}$ on the CV tier has two graphemes which are, however, realized as one sound segment while the second $C$ has only one segment. The combination of the two $\mathrm{C}$ elements on the $\mathrm{CV}$ tier is what causes the occurrence of the complex onset with an affricate and a glide shown in Figure 10.

\section{Conclusions}

Olutura has a total of seven syllable structures. Five of the syllable structures have already been identified by scholars of Bantu languages including Kiswahili; these are: $\mathrm{V}, \mathrm{CV}, \mathrm{CVV}, \mathrm{CCV}$ and CGV. The sixth syllable structure, VV which represents a long vowel was found to occur in the initial word position. The seventh syllable structure is that of GGV which has two glides in the onset and a vowel. The VV and GGV syllable structures are marked in Olutura because their occurrence in Olutura word categories and in initial, medial and final word positions is sparse. All the syllable structures discussed in this paper show that Olutura has an open syllable structure system because all of them end with vowel sounds. The composition of the syllable in Olutura is such that glides can only be 
syllabified as part of the onset but not the nucleus because they function as consonants in the subject dialect. This study also concludes that the sonority scale of Olutura can be helpful in predicting the sound segments that can combine in the formation of the complex onset in this dialect. The use of CV Phonology was instrumental, not only in establishing the syllable structures, but also in discussing their composition in the sound system of Olutura. It is projected that the discussion of the syllable structures of Olutura in this study is important in the comparative dialectology of, not just the dialects in the Luyia continuum of dialects, but other Bantu languages in phonology and other areas of linguistics. This paper, therefore, makes a contribution towards the classification of Olutura as a dialect of the Luyia continuum of dialects.

\section{REFERENCES}

[1] Angogo, R. M. (1980).Linguistic and Attitudinal Factors in the Maintenance of Luhya Group Identity. Published PhD Thesis. The University of Texas at Austin.

[2] Marlo, M. (2008).Tura Verb Tonology. Studies in African Linguistics. 37(2). 153-243.

[3] Katamba, F. (1989).An Introduction to Phonology. UK: Longman Group.

[4] Bauer, L. (1988).Introduction to Linguistic Morphology. Edinburgh: Edinburgh University Press.

[5] Hooper, J.B. (1976). An Introduction to Natural Generative Phonology. New York: Academic Press.

[6] Clements G. N. and Keyser, J. (1983). CV Phonology: A Generative Theory of the Syllable. Cambridge Mass: MIT Press.

[7] Greenberg, J.H. (1978). Generalizations about Numeral Systems. In J.H. Greenberg, C.A. Ferguson \& M.Edith (Eds,), Universals of Human Language. (249-295). Stanford: Stanford University Press.

[8] Harrington, J. \& Cox, F. (2009).Phonetics and Phonology; the Syllable and Phonotactic Constraints. Sydney: Macquire University Press

[9] Lass, R. (1984). Phonology: An Introduction to Basic Concepts. Cambridge University Press.

[10] Casali, R.F. 2011. Hiatus resolution. In M. van Oostendorp, C.J. Ewen, E. Hume and K. Rice (Eds.) The Blackwell companion to phonology. Malden, MA, Oxford: Wiley Blackwell Publishers. pp. 1434-1460.

[11] Katamba, F. (1993).Morphology. Palgrave. Macmillan Press Ltd.

[12] Odden, D. (2015).Bantu Phonologye. In Linguistics, Phonetics and Phonology. DOI: 10.1093/oxfordhb/978019 9935345.013.59

[13] McCarthy J.J. and Prince, A. S. (1993a).Generalized Alignment. In G.E. Booji and J. Van Marle (Eds.),
Yearbook of Morphology. Dortrecht: Kluwer. 80-150.

[14] Wasike, A. (2004).Hiatus Resolution in Lubukusu. Published MA Desertation, Cornell University.

[15] Savala, A. (2005).The TonalPatterns of Lwitakho. Unpublished MA Thesis. Kenyatta University.

[16] Blevins, J. (1995). The Syllable in Phonological Theory. In J. Goldsmith (Ed.), The handbook of Phonological Theory. Cambridge Mass: Blackwell.

[17] Goldsmith, J. (2011). The Syllable. In J, Goldsmith, J. Riggle and L.C. Yu (Eds.), The handbook of Phonological Theory (2nd Ed). Malden MA: Blackwell

[18] Etakwa, E., Shivachi, C. \& Ong’onda, N.(2015). The Olunyala (K) Syllable Onset. International Journal of Scientific Research and Publications, 162-167.

[19] Parker, S. (2002).Quantifing the Sonority Hierachy. University of Massachussetts Amherst Dissertation. www.gial.edu/documents/Parker dissertation.pdf 